\title{
How anxious were Quebec healthcare professionals during the first wave of the COVID-19 pandemic? A web-based cross-sectional survey
}

Jude Emmanuel Cléophat ${ }^{\mathrm{a}}$, Philippe Simon ${ }^{\mathrm{b}}$, Gilles Chiniara ${ }^{\mathrm{c}}$, Liette St-Pierre ${ }^{\mathrm{d}}$, Eusèbe Ahossi ${ }^{\mathrm{e}}$, Maman Joyce Dogba ${ }^{\mathrm{f}}$, Christophe Chénier ${ }^{\mathrm{g}}$, Éric Dubuc ${ }^{\mathrm{b}}$, Caroline Landry ${ }^{\mathrm{b}}$, Nicolas Vonarx ${ }^{\mathrm{a}}$ and Bruno Pilote ${ }^{\mathrm{a}, \mathrm{h}, *}$

${ }^{a}$ Faculty of Nursing, Laval University, Quebec City, QC, Canada

${ }^{\mathrm{b}}$ Faculty of Medicine, Laval University, Quebec City, QC, Canada

${ }^{\mathrm{c}}$ Department of Anesthesiology and Intensive Care, Faculty of Medicine, Laval University, Quebec City, QC, Canada

${ }^{\mathrm{d}}$ Department of Nursing, Quebec University in Trois-Rivières, Trois-Rivières, QC, Canada

${ }^{\mathrm{e}}$ Faculty of Nursing, University of Abomey-Calavi, Cotonou, Benin

${ }^{\mathrm{f}}$ Department of Family Medicine and Emergency Medicine, Faculty of Medicine, Laval University, Quebec City, $Q C$, Canada

${ }^{\mathrm{g}}$ Faculty of Education, University of Montreal, Montreal, QC, Canada

${ }^{\mathrm{h}}$ Research Center for Sustainable Health, Laval University, Quebec City, QC, Canada

\begin{abstract}
.
BACKGROUND: The coronavirus disease 2019 (COVID-19) pandemic may cause significant anxiety among healthcare professionals (HCPs). COVID-19-related psychological impacts on HCPs in Western countries have received relatively little attention.

OBJECTIVE: This study aims to assess the levels of anxiety in HCPs working in the province of Quebec (Canada) during the first wave of the COVID-19 pandemic and identify factors associated with changes in anxiety scores.

METHODS: An exploratory online cross-sectional survey was conducted among Quebec HCPs from April to July 2020. The Spielberger's State-Trait Anxiety Inventory (STAI) was used to measure state anxiety among HCPs. Descriptive and multivariate analyses were performed.

RESULTS: A total of $426 \mathrm{HCPs}$ completed the survey. Anxiety scores ranged from 20 to 75 points, with 80 being the highest possible value on the STAI scale. Being a female HCP [ $B=5.89,95 \%$ confidence interval (CI): 2.49-9.3] and declaring having the intention to avoid caring for patients with COVID-19 $(B=3.75,95 \%$ CI: $1.29-6.22)$ were associated with increased anxiety scores. Having more years of experience was associated with decreased anxiety scores $[B=-0.2,95 \%$ CI: $-0.32-(-0.08)]$.
\end{abstract}

\footnotetext{
*Address for correspondence: Dr. Bruno Pilote, Faculty of Nursing, Laval University, Pavillon Ferdinand-Vandry, 1050
} 
CONCLUSION: Organizational strategies aimed at preventing and relieving anxiety should target junior female HCPs who express the intention to avoid caring for patients with COVID-19. Seniority could become an important criterion in selecting frontline HCPs during pandemics. Further studies are needed to comprehensively examine the impacts of the COVID-19 pandemic on Canadian HCPs and identify evidence-based coping strategies.

Keywords: Canada, anxiety, health personnel, surveys and questionnaires, multivariate analysis

\section{Introduction}

The first case of coronavirus disease 2019 (COVID-19) in Canada was diagnosed on January 25, 2020 [1]. The first cases in Quebec, a Frenchspeaking province of Canada, were identified by the end of February 2020 [2]. As of March 30, 2021, thirteen months later, Quebec has reported the second-largest number of cases in Canada with 310,066 people diagnosed with COVID-19 and 10,658 related deaths [3]. Healthcare professionals (HCPs) are at significant risk of contracting the severe acute respiratory syndrome coronavirus 2 (SARSCoV-2), the causative agent of COVID-19, due to repeated exposure to patients, colleagues, and infectious materials, lack of personal protective equipment (PPE), or failure to comply with infection prevention guidelines [4-9]. A higher incidence of the disease has been observed among nurses and female HCPs while higher proportions of deaths have been reported among male and older HCPs [10-15]. Fear of contracting, spreading, and dying from COVID-19, inadequate knowledge of the disease, organizational issues (lack of PPE, ventilators, or intensive-care unit beds, increased workload, rapidly changing protocols...), and changes in personal life may cause anxiety and other deleterious psychological impacts (stress, depression, burnout, and post-traumatic stress disorder) among HCPs [16-18]. A recent umbrella review of seven meta-analyses revealed a pooled prevalence of anxiety in HCPs that ranged from $22 \%$ [95\% confidence interval (CI): $12.7-35.8$ ] to $33 \%$ (95\% CI: 24-45) [19].

Studies that have examined human behavior in fearful or anxiety-provoking situations have suggested that fear and individual values can influence decision-making [20-24]. Exposure to infected patients, fear of contracting the infectious pathogen and contaminating family members and friends have already been major stressors for HCPs during previous outbreaks [25-29]. Such stressors have fueled reluctance to care for affected patients in pandemic times among HCPs and may lead to absenteeism or defection [29, 30]. Anxiety in HCPs may also negatively impact the quality of care to patients [31]. Time spent with patients suspected of or diagnosed with COVID-19 and the nature of the exposure to such patients (performing droplet/aerosol-generating procedures, for instance) may vary from one HCP or professional group to another [32-35]. These factors can influence HCPs' perception of their risk of contracting the SARS-CoV-2 and their anxiety levels [36-38]. Anxiety prevalence and severity may also vary by organization [39], or health jurisdiction [38]. Thus, it seems relevant to further investigate anxiety in HCPs to inform tailored management approaches. Very little research has examined COVID-19-related anxiety in non-Asiatic HCPs [40]. Previous Canadian studies have reported an anxiety prevalence ranging from $47 \%$ to $67 \%$ among HCPs, and anxiety risk factors included concerns for personal and family wellness and perceived inadequacy of protective equipment and strategies [41-45]. However, these studies targeted HCPs seeking psychological support [41] or physician and nurse subgroups $[42,43]$. They involved relatively small samples [42, 43], did not always use validated tools to assess anxiety levels [43] and restricted their analyses to a single anxiety risk factor [44], or did not examine the statistical relationship between anxiety scores and risk factors [42]. In addition, these studies surveyed very few to no HCPs from the province of Quebec despite the important burden of the pandemic in this province [41-45]. Therefore, this study was undertaken to assess the levels of anxiety in Quebec HCPs during the first wave of the COVID-19 pandemic and identify the socio-professional characteristics of HCPs that are associated with changes in anxiety scores. Given the exploratory nature of this study, no a priori hypothesis was formulated.

\section{Materials and methods}

\subsection{Study design, setting, and participants}

A web-based cross-sectional survey was conducted among Quebec HCPs working in all healthcare settings. An invitation to participate in the study 
was sent to regional health organizations, professional societies, the Collège des Médecins du Québec (Quebec College of Physicians), and the Ordre professionnel des inhalothérapeutes du Québec (College of Respiratory Therapists of Quebec). The invitation message contained a link to the study website (www.recherche-covid-19.com). The webmaster of each organization was responsible for disseminating the invitation to members via Facebook and mailing lists. According to the snowball sampling technique, the respondents were further encouraged to forward the invitation message to colleagues who might be interested in participating in the study.

\subsection{Collection tool}

The study questionnaire was developed by the research team based on the study objectives, expert opinions, and literature data. Since profession and exposure to infected patients were risk factors for anxiety in previous pandemics [25-29] and some HCPs are said to be reluctant to work during health crises [29, 30], the survey questionnaire was built not only to estimate anxiety scores in HCPs regarding the COVID-19 pandemic but also to document their socio-professional characteristics, assess their degree of exposure and willingness to provide care to patients with COVID-19.

The questionnaire was divided into three sections. The first section included 9 items and allowed respondents to provide their first and last name, profession, postal code, and affiliation. The respondents could also report the presence of COVID-19 cases in their department and whether they had been caring for such patients.

The second section contained 16 items and focused on the respondents' sociodemographic information (age, gender, relationship status, number of years of work experience, number of dependents), previous diagnosis of COVID-19, previous experience in critical care, and current diseases and medication. Two items asked respondents about their intention to avoid caring for patients with COVID-19: "Are you thinking about or are you looking for means to avoid caring for patients with COVID-19?" hereafter item 22; "If a situation allowed you to avoid caring for someone infected with COVID-19, would you take this opportunity?" hereafter item 25 . The first item was dichotomous: "Yes" $=1$ and "No" $=0$. The second item had three possible values: "Yes" =2, "not at the moment" $=1$, and "No" $=0$. Also, two questionnaire items asked respondents about actions taken to
Table 1

Items of the STAI-Y subscale intended to measure state anxiety

\begin{tabular}{llcl}
\hline $\begin{array}{l}\text { Item } \\
\text { number }\end{array}$ & Item & $\begin{array}{c}\text { Item } \\
\text { number }\end{array}$ & Item \\
\hline 1 & I feel calm & 11 & I feel self-confident \\
2 & I feel secure & 12 & I feel nervous \\
3 & I am tense & 13 & I am jittery \\
4 & I feel strained & 14 & I feel indecisive \\
5 & I feel at ease & 15 & I am relaxed \\
6 & I feel upset & 16 & I feel content \\
7 & I am presently worrying & 17 & I am worried \\
& over possible & & \\
& misfortunes & 18 & I feel confused \\
8 & I feel satisfied & 19 & I feel steady \\
9 & I feel frightened & 20 & I feel pleasant \\
10 & I feel comfortable & & \\
\hline
\end{tabular}

avoid caring for patients with COVID-19: "Have you ever taken a measure, which has not worked, to try to avoid caring for someone infected with COVID-19," "Have you taken any successful action to avoid having to intervene with people with COVID-19?" Both items were dichotomous with two possible values: "Yes" $=1$ and "No" = 0 .

The third section of the questionnaire consisted of 20 items from the Spielberger's State-Trait Anxiety Inventory (STAI-Y) (Table 1) [46]. These items constitute a subscale called STAI-Y-1 that is intended to measure state anxiety [47]. STAI-Y has good psychometric properties and has been widely used in research [48-51]. A validated French version of the STAI-Y-1 was used in this study as it is considered to be statistically equivalent to the original version [52]. STAI-Y-1 items are scored on a 4-point Likert scale ( $1=$ "not at all," $2=$ "somewhat," $3=$ "moderately," $4=$ "very much so"). Ten items refer to the presence of anxiety (anxiety-present subscale). Another ten refer to its absence (anxiety-absent subscale) and are reverse scored, 4 meaning "not at all" and 1 meaning "very much so." The STAI-Y-1 scores can range between 20 and 80, higher scores indicating higher levels of anxiety. The study questionnaire was available online from April 7, 2020, to July 31, 2020.

\subsection{Data analysis}

Categorical variables were reported as proportions and continuous variables, as means and standard deviations (SDs). Complete case analyses were conducted. A variable named "Intention-to-avoid" was created by merging items 22 and 25 which relate to HCPs' intention to avoid caring for patients with COVID-19 (Table 2). This variable was scored on an ordinal scale ranging from 0 to 3 where 0 means 
Table 2

Components and potential values of the intention-to-avoid score

\begin{tabular}{|c|c|c|c|c|c|c|c|}
\hline \multirow{3}{*}{$\begin{array}{l}\text { Merged items } \\
\text { Are you thinking about or are you looking for means to } \\
\text { avoid caring for COVID-19 patients? (item 22) }\end{array}$} & \multirow{2}{*}{$\begin{array}{l}\text { Initial values of the items } \\
\text { Yes }=1\end{array}$} & \multicolumn{6}{|c|}{$\begin{array}{l}\text { Components of } \\
\text { the intention- } \\
\text { to-avoid score }\end{array}$} \\
\hline & & 1 & 1 & 1 & - & - & \\
\hline & No $=0$ & - & - & - & 0 & 0 & 0 \\
\hline If a situation allowed you to avoid caring for someone & Yes $=2$ & 2 & - & - & 2 & - & - \\
\hline infected with COVID-19, would you take this & Not at the moment $=1$ & - & 1 & - & - & 1 & - \\
\hline opportunity? (item 25 ) & No $=0$ & - & - & 0 & - & - & 0 \\
\hline & $\begin{array}{l}\text { Potential values of the intention- } \\
\text { to-avoid score }\end{array}$ & 3 & 2 & 1 & 2 & 1 & 0 \\
\hline
\end{tabular}

Table 3

Factors considered in modeling the anxiety scores, and their coefficient

\begin{tabular}{|c|c|c|c|c|c|c|}
\hline \multirow{2}{*}{$\begin{array}{l}\text { Variable } \\
\text { Intercept }\end{array}$} & \multirow{2}{*}{$\begin{array}{c}\begin{array}{c}\text { Standardized } \\
\text { coefficient }\end{array} \\
0\end{array}$} & \multirow{2}{*}{$\begin{array}{c}\begin{array}{c}\text { Unstandardized } \\
\text { coefficient }\end{array} \\
33.17\end{array}$} & \multirow{2}{*}{$\begin{array}{c}\begin{array}{c}\text { Standard } \\
\text { error }\end{array} \\
2.81\end{array}$} & \multicolumn{2}{|c|}{$95 \% \mathrm{CI}$} & \multirow{2}{*}{$\begin{array}{l}p \text {-value } \\
<0.001\end{array}$} \\
\hline & & & & 27.64 & 38.7 & \\
\hline Female HCP & 0.16 & 5.89 & 1.73 & 2.49 & 9.3 & 0.0007 \\
\hline Other healthcare professional & 0.05 & 1.47 & 1.61 & -1.70 & 4.64 & 0.43 \\
\hline Respiratory therapist & 0.02 & 1.18 & 1.99 & -2.72 & 5.08 & 0.55 \\
\hline Physician & 0.08 & 3.16 & 1.81 & -0.39 & 6.71 & 0.08 \\
\hline Orderly & 0.03 & 1.65 & 2.55 & -3.36 & 6.67 & 0.52 \\
\hline Paramedic & 0.02 & 1.3 & 3.08 & -4.77 & 7.36 & 0.67 \\
\hline Care for patients with COVID-19 & 0.1 & 2.47 & 1.27 & -0.03 & 4.98 & 0.05 \\
\hline Work in a hospital setting & 0.05 & 1.19 & 1.66 & -2.07 & 4.44 & 0.47 \\
\hline Work in internal medicine & -0.08 & -2.11 & 1.75 & -5.55 & 1.33 & 0.23 \\
\hline Work in critical care services & -0.0006 & -0.05 & 1.19 & -2.4 & 2.29 & 0.96 \\
\hline Patients with COVID-19 in department & 0.05 & 1.11 & 1.25 & -1.35 & 3.56 & 0.38 \\
\hline Years of work experience & -0.16 & -0.2 & 0.06 & -0.32 & -0.08 & 0.001 \\
\hline Mood disorders & 0.02 & 1.15 & 2.57 & -3.9 & 6.21 & 0.65 \\
\hline Avoid caring for patients with COVID-19 & -0.01 & -0.64 & 2.37 & -5.3 & 4.02 & 0.79 \\
\hline Mild intention to avoid caring for patients with COVID-19 & 0.15 & 3.75 & 1.25 & 1.29 & 6.22 & 0.003 \\
\hline Moderate intention to avoid caring for patients with COVID-19 & 0.21 & 7.63 & 1.71 & 4.27 & 10.99 & $<0.001$ \\
\hline Strong intention to avoid caring for patients with COVID-19 & 0.32 & 14.62 & 2.41 & 9.89 & 19.36 & $<0.00$ \\
\hline Living as a couple & -0.0003 & 1.59 & 1.38 & -1.13 & 4.31 & 0.25 \\
\hline Having dependents & 0.05 & -0.01 & 1.18 & -2.32 & 2.31 & 0.99 \\
\hline Previous diagnosis of COVID-19 & -0.02 & -1.01 & 2.43 & -5.78 & 3.76 & 0.68 \\
\hline
\end{tabular}

that the respondent answered "No" to both items (no intention at all to avoid caring for patients with COVID-19), and 3 means that the answer was "Yes" to both items (strong intention). The intention-toavoid score was 2 (moderate intention) when the answer was "Yes" to item 22 and "Not at the moment" to item 25, or "No" to item 22, and "Yes" to item 25. The intention-to-avoid score was 1 (mild intention) when the answer was "yes" to item 22 and "No" to Item 25 , or "No" to Item 22 and "Not at the moment" to item 25. The variable "Avoidance" was also created by combining the two variables related to actions taken by respondents to avoid caring for patients with COVID-19, yielding a dichotomous result: "Yes" $=1$, "No" $=0$.

The STAI-Y-1 anxiety scores are calculated in three steps. First, the aggregate scores for the anxietypresent subscale and the anxiety-absent subscale are calculated by adding up the scores of the items within each subscale. Secondly, the aggregate score for the anxiety-absent subscale is subtracted from that of the anxiety-present subscale. Thirdly, a constant value of 50 is added to the resulting score to obtain the final anxiety score. A multiple linear regression analysis was performed to identify factors that are associated with anxiety scores. The associations between the factors included in the model and the anxiety scores were presented as mean differences in anxiety scores. These differences were reported as unstandardized (B) and standardized Beta coefficients $(\beta)$ (Table 3). A correlation analysis was performed, and no collinearity issue was found between the factors considered in the model (Supplementary Table 1). A one-way ANOVA was used to compare the means of anxiety scores of the professional groups represented in the study. A 2-tailed $p$-value $<0.05$ was 
indicative of statistical significance. Statistical analyses were performed using R software (Version 4.0.3, The R Foundation for Statistical Computing, Vienna, Austria).

\subsection{Ethical considerations}

This study was approved by the Research Ethics Review Board of Laval University (Approval number: 2020-122/16-04-2020). Participants consented electronically to the study before starting the survey. They were provided with all relevant study information and were informed that they could leave the study at any time and that their answers were to remain confidential. The collected data were stored in a secure server at Laval University (Quebec City, Canada) and anonymized before being analyzed.

\section{Results}

A total of 557 HCPs answered the questionnaire among whom 131 were excluded as they did not answer all the survey questions. Thus, the analytic sample consisted of 426 HCPs (Table 4). They were mostly female (88\%), and aged 18 to 80 with a mean of $13.67(\mathrm{SD}=9.68)$ years of experience. Just over half of respondents were nurses or nursing assistants $(53 \%)$. They worked in various departments mainly in internal medicine (12\%), community health (10.33\%), emergency $(9.62 \%)$, and residential and long-term care centers $(8.69 \%)$. The majority (58\%) reported working or having worked in critical care services. Just over half of HCPs (53\%) confirmed the presence of patients with COVID-19 in their department and caring for such patients. Almost 6\% declared having been diagnosed with COVID-19. Most HCPs lived as a couple (78\%) and had children or elderly dependents $(62 \%)$. Twenty $(5 \%)$ reported suffering from mood disorders before the pandemic.

The STAI-Y-1 anxiety scores ranged from 20 to 75 points among respondents, with a quarter of them having scores ranging from 51 to 75 points (Supplementary Table 2 ). The mean anxiety score for the whole sample was $42(\mathrm{SD}=11.8)$. Female HCPs had a mean anxiety score of 43 points $(S D=11.61)$ and males had a mean of 37 points $(\mathrm{SD}=12.03)$ (Supplementary Tables 3 and 4 ). The mean anxiety scores in female HCPs ranged from 42 to 45 points across professional groups, with paramedics having the highest mean score. The mean anxiety scores in males varied from 32 to 46 points across
Table 4

Characteristics of the study population $(\mathrm{N}=426)$

\begin{tabular}{|c|c|c|c|c|c|}
\hline \multicolumn{4}{|l|}{ Profession } & \multicolumn{2}{|c|}{$(\mathrm{n}, \%)$} \\
\hline \multicolumn{4}{|l|}{ Physician } & \multicolumn{2}{|c|}{$59(13.85)$} \\
\hline \multicolumn{4}{|l|}{ Nurse } & \multicolumn{2}{|c|}{$225(52.82)$} \\
\hline \multicolumn{4}{|l|}{ Orderly } & \multicolumn{2}{|c|}{$23(5.4)$} \\
\hline \multicolumn{4}{|c|}{ Respiratory therapist } & \multicolumn{2}{|c|}{$42(9.86)$} \\
\hline \multicolumn{4}{|c|}{ Paramedic } & \multicolumn{2}{|c|}{$19(4.46)$} \\
\hline \multicolumn{4}{|l|}{ Other HCPs* } & \multicolumn{2}{|c|}{$58(13.62)$} \\
\hline \multicolumn{6}{|l|}{ Age groups } \\
\hline \multicolumn{4}{|l|}{$<30$} & \multicolumn{2}{|c|}{$82(19.25)$} \\
\hline \multicolumn{4}{|l|}{$30-39$} & \multicolumn{2}{|c|}{$158(37.09)$} \\
\hline \multicolumn{4}{|l|}{$40-49$} & \multicolumn{2}{|c|}{$123(28.87)$} \\
\hline \multicolumn{4}{|l|}{$50-59$} & \multicolumn{2}{|c|}{$48(11.27)$} \\
\hline$\geq 60$ & & & & 15 & $3.52)$ \\
\hline Gender & & & & & \\
\hline Female & & & & 373 & 37.56) \\
\hline Male & & & & 53 & 2.44) \\
\hline Relationship statu & & & & & \\
\hline Live in couple & & & & 332 & 77.93) \\
\hline Single & & & & 94( & 2.07) \\
\hline Dependents & & & & & \\
\hline Yes & & & & 263 & 51.74) \\
\hline No & & & & 163 & $38.26)$ \\
\hline Work experience i & years & & & & \\
\hline $0.5-5$ & & & & & (23) \\
\hline $6-10$ & & & & 85( & 9.95) \\
\hline $11-15$ & & & & 89( & 0.89) \\
\hline $16-20$ & & & & 68 & 5.96) \\
\hline$>20$ & & & & 86( & 0.19) \\
\hline Healthcare setting & & & & & \\
\hline Hospital & & & & 282 & $56.20)$ \\
\hline Community & & & & 144 & $33.80)$ \\
\hline Work in critical ca & service & & & & \\
\hline Yes & & & & 248 & 58.22) \\
\hline No & & & & 178 & 41.78) \\
\hline Treat patients witl & COVID- & & & & \\
\hline Yes & & & & 226 & $53.05)$ \\
\hline No & & & & 200 & 46.95) \\
\hline Prior COVID- $19 c$ & gnosis & & & & \\
\hline Yes & & & & 24 & 5.63) \\
\hline No & & & & 402 & $94.37)$ \\
\hline Mood disorders & & & & & \\
\hline Yes & & & & 20 & 4.69) \\
\hline No & & & & 406 & 95.31) \\
\hline & Mean & Median & SD & Min & Max \\
\hline Age & 38.75 & 38 & 10.14 & 18 & 80 \\
\hline Work experience & 13.67 & 12 & 9.68 & 0.5 & 50 \\
\hline
\end{tabular}

*Physiotherapist (18), occupational therapist (5), kinesiologist (2), Pharmacist (3), nutritionist (5), speech therapist (2), social worker (2), Management and clerical staff (12), technician (laboratory, cardiology, and medical imaging) (5).

professional groups, with orderlies having the highest mean score. There was no statistically significant difference in mean anxiety scores between professional groups whether disaggregated according to gender or not (Figs. 1 and 2) (Females: $F_{(5,367)}=0.16$, $p=0.98$; Males: $F_{(5,47)}=1.04, p=0.40$; Both genders: $\left.F_{(5,420)}=0.35, p=0.88\right)$. Thirty-two percent, $13 \%$, and $7 \%$ of HCPs expressed, respectively, mild, 


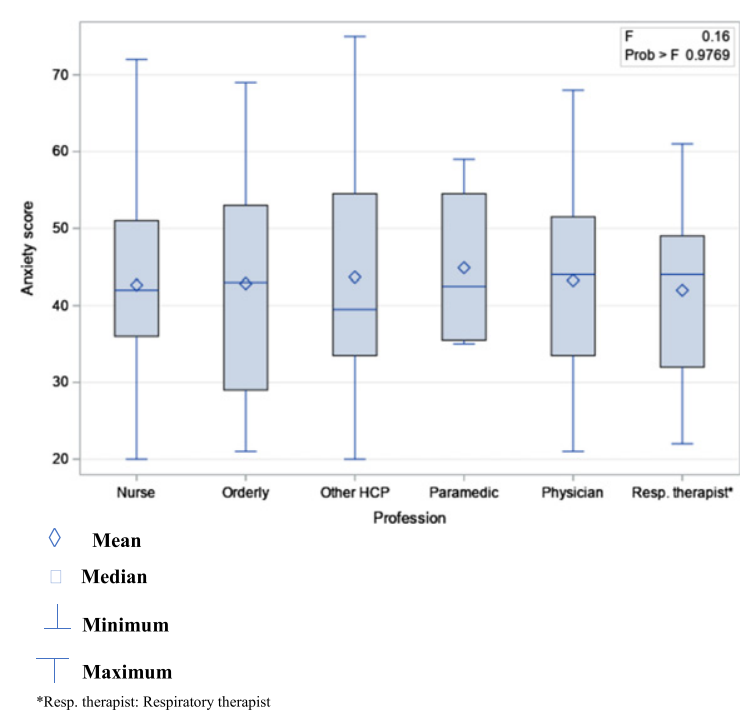

Fig. 1. Means of anxiety scores in women by professional group.

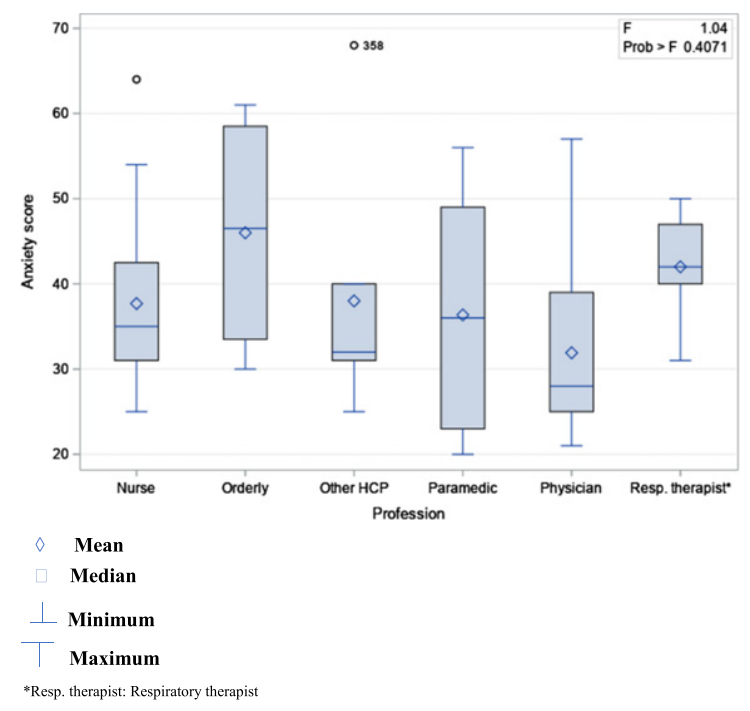

Fig. 2. Means of anxiety scores in men by professional group.

moderate, and strong intention to avoid providing care to patients with COVID-19. Few HCPs $(6.57 \%)$ stated having taken steps to avoid caring for patients with COVID-19.

Fourteen variables including two dummy variables (Profession and Intention to avoid caring for patients with COVID-19) were entered into the multiple linear regression model which was statistically significant $\left(F_{(20,405)}=4.2 ; p<.0001\right)$ and explained $13 \%$ of the variance of the anxiety scores (adjusted $\mathrm{R}^{2}$ ) (Table 3). More specifically, this model showed that the mean anxiety score in female HCPs was significantly higher $[B=5.89,95 \%$ CI: $2.49-9.3, p<.0007]$ than in male HCPs when adjusted for all other factors considered in the model. For HCPs, each year of work experience was associated with a 0.2 reduction in mean anxiety score [95\% CI: $-0.32-(-0.08)$, $p=0.001]$. The intention to avoid caring for patients with COVID-19 was significantly associated with increased anxiety score. Indeed, HCPs with mild, moderate, and strong intention to avoid providing care to patients with COVID-19 had, respectively, mean anxiety scores of 3.75 (95\% CI: 1.29-6.22), 7.63 (95\% CI: 4.27-10.99), and 14.62 (95\% CI: 9.89-19.36) points higher than the mean score of HCPs who did not express the intention to withdraw from care to patients with COVID-19. Standardized coefficients showed a stronger association between the anxiety scores and moderate $(\beta=0.21)$ and strong $(\beta=0.32)$ intention to avoid caring for patients with COVID-19 compared to the other factors of the model. No association was found between caring for patients with COVID-19 and anxiety scores. The same trend was observed for living as a couple, having dependents, and a previous diagnosis of COVID-19.

\section{Discussion}

This study showed that, during the first wave of the COVID-19 pandemic, anxiety scores among Quebec HCPs varied widely, with a quarter of them showing scores approaching the highest possible value of the STAI-Y scale. Being a female HCP and declaring having the intention to avoid caring for patients with COVID-19 were both associated with increased anxiety score. Seniority at work was associated with decreased anxiety score.

Few studies have used the STAI-Y scale to evaluate anxiety levels in HCPs during the first months of the COVID-19 pandemic. Mean anxiety scores similar to [53-55] or higher [56-58] than those observed in the present work were reported in such studies. The female gender was also found to be predictive of increased anxiety score among HCPs in previous studies [54, 56, 58-61]. Yet, in Karabulut et al., Turkish male HCPs had a higher mean anxiety score than females [53]. Cultural differences were suggested by the authors to explain such a contrast with published studies. Consistent with our findings, previous studies have revealed a statistically significant association between greater work experience and decreased anxiety score [56, 60, 62]. Nevertheless, in BahadirYilmaz and Yuksel, seniority predicted an increase in scores [58]. 
Although differences in mean anxiety scores have been previously observed between and within professional groups [54, 56, 63], no statistically significant difference was found in the present study between such groups. The high proportion of women (42\% to 93\%) across these groups in our study might explain the absence of difference. In line with our findings, Liang et al. found no statistical difference in anxiety levels between frontline and non-frontline HCPs [64]. Conversely, Milgrom et al. found a statistically significant increase in anxiety scores among HCPs working in a hospital providing care to patients with COVID19 [54]. Several other studies reported higher anxiety scores in frontline HCPs [65-69] whereas Mohd Noor et al. found a higher mean anxiety score among non-frontline HCPs [70]. Furthermore, HCPs have expressed the intention to avoid caring for patients infected with COVID-19 in prior studies [71-75]. Fear of getting infected and contaminating family members, lack of PPE, and excessive workload were among the reasons put forward to justify such a stance.

The factors (gender, seniority at work) found in this study to be associated with increased anxiety scores could be included in the classification made by Vindegaard et al. of risk factors for anxiety among HCPs facing the COVID-19 pandemic [76]. Indeed, in a systematic review, the authors grouped such factors into four categories: 1) sociodemographic factors (age, educational level, marital status, number of children); 2) current or past medical history (psychiatric disorders, substance abuse); 3) psychological and social factors (poor self-perceived health status, pandemic impacts on daily life, lack of family and social support); 4) job-related factors (exposure to patients with COVID-19, lack of work experience, high social media exposure).

Higher anxiety scores in female HCPs, as demonstrated in our study, might have a physiological basis. Indeed, Seo et al. used magnetic resonance imaging to investigate the brain's response to stressinducing images in 96 healthy men and women [77]. Men's brain response to anxiety was characterized by greater activation of areas involved in motor functions, including the caudate, thalamus, midbrain, and anterior cingulate cortex [78-81]. Women were found to produce a greater response in the insula, temporal gyrus, occipital lobe, and prefrontal-parietal cortices which are involved in emotional arousal and regulation, and cognitive processes such as the understanding of self, others, and environment [82, 83]. The authors concluded that women might have difficulty controlling hyperactivity in these areas and might tend to be more involved than men in overanalyzing, rumination, and producing negative thoughts in the face of stressful events, which could increase their risk of developing anxiety disorders.

Furthermore, the association observed here between seniority and decreased anxiety scores might result from the skill proficiency of experienced HCPs, their confidence in their skills, or their psychological preparedness to deal with unexpected challenges and a new threat to their health [84]. Given their position, senior HCPs may also have limited exposure to patients with COVID-19, which may reduce fear, stress, and the risk of developing anxiety [85]. In addition, they may have fewer career goals to pursue, and less financial pressure or family obligations $[85,86]$ since they may have already achieved some stability in their careers and may be experiencing a sense of accomplishment and satisfaction with such aspects of their life.

Based on our results, surveying HCPs' willingness to provide care to patients infected with COVID19 may help identify professionals with increased levels of anxiety. Indeed, in the present study, one third of HCPs expressed a mild to strong intention to avoid providing care to patients with COVID-19. Additionally, anxiety scores tended to increase with a higher intention by HCPs to avoid treating patients with COVID-19. Such intention may be part of the continuum from the perceived threat of COVID-19 to job abandonment through anxiety, and psychological withdrawal [87]. Absenteeism has been observed in HCPs during the first wave of the pandemic and might become an obstacle to continuous delivery of health care and services if not appropriately addressed in pandemic times $[88,89]$.

The absence of association between caring for patients with COVID-19 and anxiety scores could be explained by HCPs' perception that such experience may help them grow as a person and professional [72]. Better knowledge of the disease and health safety measures $[7,90]$, the experience gained since the outbreak of the pandemic [91], and the increased availability of PPE [7] may have strengthened the confidence of Quebec HCPs caring for patients with COVID-19, thus reducing their anxiety level.

The strength of this study lies in reaching a relatively large and diverse sample of HCPs among whom more than half were involved in providing care to patients with COVID-19. It also used a validated tool and multivariate analyses to provide a rare description of state anxiety and associated factors 
in Canadian HCPs. However, this study has some limitations. The invitation to the study was sent to specific professional societies and health organizations through e-mails and Facebook, thus excluding nonmembers of such organizations and non-Facebook users who did not receive the survey link by e-mail. Besides, some professional groups including pharmacists, social workers, nutritionists, occupational therapists were not adequately represented. Thus, the study sample might not be representative of the entire Quebec HCPs population, limiting the generalizability of the study findings. We also found that $58 \%$ of participants were working or had worked in intensive care units. Such HCPs may have dealt with patients with COVID-19 that were critically ill. The associated psychological distress might have motivated them more to participate in the study than their peers who do not work in intensive care units. This potential selection bias could have led to overestimating the anxiety scores and the outcomes of the regression model. Furthermore, the psychometric properties of the questionnaire items related to the intention and actions taken by HCPs to avoid caring for patients with COVID-19 have not been evaluated. Study data were self-reported, and as such, are subject to social desirability which may lead to overestimating or underestimating anxiety scores, or underestimating scores assigned to the intention or actions taken to avoid providing care to patients with COVID-19. Finally, other risk factors for anxiety could have been considered in multivariate analyses including duration of working shifts, workload, the economic impacts of the pandemic [56], the availability, access, and quality of PPE [92], the frequency, duration, and nature of exposure to patients with COVID-19 [32], familial, social, and organizational support, the adequacy of the information provided about COVID-19, and self-perceived competency in caring for patients with the disease [93]. Sets of these factors could better explain the variance of the anxiety scores.

This study has implications for health personnel management and research. Health organizations should develop interventions to prevent anxiety, screen HCPs, monitor their mental health, and support and orientate those in need towards specialized resources. Preventive interventions should target potential sources of anxiety and could draw from the five lines of action proposed by Shanafelt et al. that consist in 1) listening and acting on HCPs' perspectives on issues related to the pandemic; 2) reducing their risk of acquiring and transmitting the virus; 3 ) providing them with training geared towards high-quality patient care; 4) meeting their family and personal needs, both physical and psychological, and 5) providing appropriate responses to the needs mentioned earlier in the event HCPs get infected [94]. Specifically, the availability of quality PPE, adequate workload, staffing and rest time, timely staff turnover, balanced time treating patients with COVID-19, and the development of recreational and rest areas could all be appropriate measures for the prevention and relief of anxiety [42, 95-98]. Clear and coherent recommendations, validated and updated information, avoiding overwatching news on COVID-19, social and familial support may also contribute to maintaining psychological stability [7, 16, 42, 61, 99]. Health organizations should promote positive coping behaviors such as physical activity, meditation, talk therapy, or virtual support groups [100]. They should also encourage HCPs to pursue psychological support as the latter might be reluctant to do so [66]. Evaluating implemented interventions may lead to adjustments of prevention and support programs and identification of cost-effective strategies [97].

Young age, work experience in a previous pandemic, and skills and knowledge about protective measures have been inconsistently reported as likely to lead HCPs to care for patients infected with COVID-19 [73]. Further research is needed to better understand factors associated with HCPs' willingness to provide care to infected patients during pandemics. Studies examining other potential psychological impacts of the pandemic on Canadian HCPs such as stress, depression, burnout, and sleep disturbances should also be undertaken. Qualitative studies are needed to identify factors that could predict or explain anxiety and other psychological impacts in Quebec HCPs. Furthermore, it is difficult to compare anxiety prevalence and severity in HCPs across studies that used the STAI-Y-1 scale during the COVID-19 pandemic as different cut-off values have been used, and the clinical significance of scores exceeding these values have not been investigated $[54,55,57,58]$. Thus, studies are needed among HCPs to find consensus on the normative values of the STAI-Y scale, and determine a cut-off point above which clinical anxiety or anxiety disorders can be legitimately suspected. The extent to which scores exceeding the cut-off value impact the quality of patient care should also be examined. Finally, although there was no statistically significant difference between professional groups in this study, the higher mean anxiety score found in orderlies warrants further investigation to confirm the observed trend and identify its determinants. 


\section{Conclusion}

This study showed that female HCPs with little experience and expressing the intention to avoid caring for patients with COVID-19 may have the highest anxiety scores. Preventive and mitigating interventions should first target HCPs with such characteristics, with the expressed intention to avoid caring for patients with COVID-19 taken as an indicator of the potential presence of symptoms of anxiety among HCPs. Seniority could be one of the criteria to identify the HCPs best suited to be assigned to the frontline during pandemics. The design and implementation of prevention, screening, psychosocial support programs, as well as appropriate treatment of HCPs could pose financial challenges to healthcare systems. However, during pandemics, such interventions have the potential to help retain HCPs, improve their quality of life and experience as professionals, create a sense of self-satisfaction, and ensure continuity and excellence in health care.

\section{Acknowledgments}

The authors thank the healthcare professionals who participated in the study for their time and valuable contribution.

\section{Conflict of interest}

The authors declare that they have no conflict of interest to disclose.

\section{Data availability}

Data supporting the findings of this study are available upon reasonable request from the corresponding author B. P.

\section{Declaration}

The authors confirm that they have reported all measures, conditions and data exclusions relevant to the study. A small sample of study participants was subsequently contacted and invited to provide their perspective on qualitative research.

\section{Funding}

This study was funded by the Canadian Institutes of Health Research. P.S. received a scholarship from the Department of Family Medicine and Emergency Medicine at the Faculty of Medicine of Laval University.

\section{Supplementary data}

The supplementary tables are available from https://dx.doi.org/10.3233/WOR-210525.

\section{References}

[1] Willows SD, Alam SB, Sandhu JK, Kulka M. A Canadian perspective on severe acute respiratory syndrome coronavirus 2 infection and treatment: how prevalent underlying inflammatory disease contributes to pathogenesis. Biochem Cell Biol. 2020

[2] Ministère de la Santé et des Services sociaux (Ministry of Health and Social Services). Coronavirus (COVID-19) Québec, Canada: Gouvernement du Québec (Government of Quebec); 2021 [updated December 23, 2020. Available from: https://msss.gouv.qc.ca/professionnels/maladiesinfectieuses/coronavirus-2019-ncov/.

[3] Ministère de la Santé et des Services sociaux (Ministry of Health and Social Services). Données sur la COVID-19 au Québec (Data on COVID-19 in Quebec) Québec: Gouvernement du Québec (Government of Quebec); 2021 [updated March, 30, 2021. Available from: https://www. quebec.ca/sante/problemes-de-sante/a-z/coronavirus2019/situation-coronavirus-quebec/\#c47900.

[4] Dev N, Kumar V, Sankar J. COVID-19 infection outbreak among health care workers: perspective from a low-middle income country. Monaldi Arch Chest Dis. 2020;90(3).

[5] Alajmi J, Jeremijenko AM, Abraham JC, Alishaq M, Concepcion EG, Butt AA, et al. COVID-19 infection among healthcare workers in a national healthcare system: The Qatar experience. Int J Infect Dis. 2020;100:386-9.

[6] Sowerby LJ, Stephenson K, Dickie A, Lella FAD, Jefferson $\mathrm{N}$, North $\mathrm{H}$, et al. International registry of otolaryngologist-head and neck surgeons with COVID-19. Int Forum Allergy Rhinol. 2020;10(11):1201-8.

[7] De Serres G, Carazo S, Lorcy A, Villeneuve J, Laliberté D, Martin R, et al. Enquéte épidémiologique sur les travailleurs de la santé atteints par la COVID-19 au printemps 2020. Québec: Institut national de santé publique du Québec; 2020.

[8] Schwartz KL, Achonu C, Buchan SA, Brown KA, Lee $\mathrm{B}$, Whelan M, et al. Epidemiology, clinical characteristics, household transmission, and lethality of severe acute respiratory syndrome coronavirus-2 infection among healthcare workers in Ontario, Canada. PLoS One. 2020;15(12):e0244477.

[9] Celebi G, Piskin N, Celik Beklevic A, Altunay Y, Salci Keles A, Tuz MA, et al. Specific risk factors for SARSCoV-2 transmission among health care workers in a 
university hospital. Am J Infect Control. 2020;48(10): 1225-30.

[10] Ing EB, Xu QA, Salimi A, Torun N. Physician deaths from corona virus (COVID-19) disease. Occup Med (Lond). 2020;70(5):370-4.

[11] Oda G, Sharma A, Lucero-Obusan C, Schirmer P, Sohoni P, Holodniy M. COVID-19 Infections Among Healthcare Personnel in the United States Veterans Health Administration, March - August, 2020. J Occup Environ Med. 2020.

[12] Hughes MM, Groenewold MR, Lessem SE, Xu K, Ussery EN, Wiegand RE, et al. Update: Characteristics of Health Care Personnel with COVID-19 - United States, February 12-July 16, 2020. MMWR Morb Mortal Wkly Rep. 2020;69(38):1364-8.

[13] Kursumovic E, Lennane S, Cook TM. Deaths in healthcare workers due to COVID-19: the need for robust data and analysis. Anaesthesia. 2020;75(8):989-92.

[14] Bandyopadhyay S, Baticulon RE, Kadhum M, Alser M, Ojuka DK, Badereddin Y, et al. Infection and mortality of healthcare workers worldwide from COVID-19: a systematic review. BMJ Glob Health. 2020;5(12).

[15] Zheng L, Wang X, Zhou C, Liu Q, Li S, Sun Q, et al. Analysis of the Infection Status of Healthcare Workers in Wuhan During the COVID-19 Outbreak: A Cross-sectional Study. Clin Infect Dis. 2020;71(16):2109-13.

[16] El-Hage W, Hingray C, Lemogne C, Yrondi A, Brunault P, Bienvenu $\mathrm{T}$, et al. [Health professionals facing the coronavirus disease 2019 (COVID-19) pandemic: What are the mental health risks?]. Encephale. 2020;46(3s):S73-s80.

[17] Fernandez R, Lord H, Halcomb E, Moxham L, Middleton $\mathrm{R}$, Alananzeh I, et al. Implications for COVID-19: A systematic review of nurses' experiences of working in acute care hospital settings during a respiratory pandemic. Int J Nurs Stud. 2020;111:103637.

[18] De Kock JH, Latham HA, Leslie SJ, Grindle M, Munoz SA, Ellis L, et al. A rapid review of the impact of COVID19 on the mental health of healthcare workers: implications for supporting psychological well-being. BMC Public Health. 2021;21(1):104.

[19] Sahebi A, Nejati B, Moayedi S, Yousefi K, Torres M, Golitaleb M. The prevalence of anxiety and depression among healthcare workers during the COVID-19 pandemic: An umbrella review of meta-analyses. Prog Neuropsychopharmacol Biol Psychiatry. 2021:110247.

[20] Ropeik D. The consequences of fear. EMBO Rep. 2004;5 Spec No:S56-60.

[21] She S, Eimontaite I, Zhang D, Sun Y. Fear, Anger, and Risk Preference Reversals: An Experimental Study on a Chinese Sample. Front Psychol. 2017;8:1371.

[22] Schlösser T, Dunning D, Fetchenhauer D. What a Feeling: The Role of Immediate and Anticipated Emotions in Risky Decisions. J Behav Decis Mak. 2013;26(1):13-30.

[23] Verplanken B, Holland RW. Motivated decision making: effects of activation and self-centrality of values on choices and behavior. J Pers Soc Psychol. 2002;82(3):434-47.

[24] Bardi A, Schwartz SH. Values and behavior: strength and structure of relations. Pers Soc Psychol Bull. 2003; 29(10):1207-20

[25] Maunder R. The experience of the 2003 SARS outbreak as a traumatic stress among frontline healthcare workers in Toronto: lessons learned. Philos Trans R Soc Lond B Biol Sci. 2004;359(1447):1117-25.

[26] Nickell LA, Crighton EJ, Tracy CS, Al-Enazy H, Bolaji Y, Hanjrah S, et al. Psychosocial effects of SARS on hospital staff: survey of a large tertiary care institution. CMAJ. 2004;170(5):793-8

[27] Koh D, Lim MK, Chia SE, Ko SM, Qian F, Ng V, et al. Risk perception and impact of Severe Acute Respiratory Syndrome (SARS) on work and personal lives of healthcare workers in Singapore: what can we learn? Med Care. 2005;43(7):676-82.

[28] Matsuishi K, Kawazoe A, Imai H, Ito A, Mouri K, Kitamura N, et al. Psychological impact of the pandemic (H1N1) 2009 on general hospital workers in Kobe. Psychiatry Clin Neurosci. 2012;66(4):353-60.

[29] Goulia P, Mantas C, Dimitroula D, Mantis D, Hyphantis T. General hospital staff worries, perceived sufficiency of information and associated psychological distress during the $\mathrm{A} / \mathrm{H} 1 \mathrm{~N} 1$ influenza pandemic. BMC Infect Dis. 2010;10:322.

[30] Bai Y, Lin CC, Lin CY, Chen JY, Chue CM, Chou P. Survey of stress reactions among health care workers involved with the SARS outbreak. Psychiatr Serv. 2004;55(9):1055-7.

[31] Weaver MD, Vetter C, Rajaratnam SMW, O'Brien CS, Qadri S, Benca RM, et al. Sleep disorders, depression and anxiety are associated with adverse safety outcomes in healthcare workers: A prospective cohort study. J Sleep Res. 2018;27(6):e12722.

[32] Heinzerling A, Stuckey MJ, Scheuer T, Xu K, Perkins $\mathrm{KM}$, Resseger H, et al. Transmission of COVID-19 to Health Care Personnel During Exposures to a Hospitalized Patient - Solano County, California, February 2020. MMWR Morb Mortal Wkly Rep. 2020;69(15):472-6.

[33] Tian Y, Gong YH, Liu PY, Wang S, Xu XH, Wang XY, et al. Infection Prevention Strategy in Operating Room during Coronavirus Disease 2019 (COVID-19) Outbreak. Chin Med Sci J. 2020;35(2):114-20.

[34] Calo F, Russo A, Camaioni C, De Pascalis S, Coppola $\mathrm{N}$. Burden, risk assessment, surveillance and management of SARS-CoV-2 infection in health workers: a scoping review. Infect Dis Poverty. 2020;9(1):139.

[35] Butler R, Monsalve M, Thomas GW, Herman T, Segre AM, Polgreen PM, et al. Estimating Time Physicians and Other Health Care Workers Spend with Patients in an Intensive Care Unit Using a Sensor Network. Am J Med. 2018;131(8):972 e9- e15.

[36] Zerbini G, Ebigbo A, Reicherts P, Kunz M, Messman H. Psychosocial burden of healthcare professionals in times of COVID-19 - a survey conducted at the University Hospital Augsburg. Ger Med Sci. 2020;18:Doc05.

[37] Amin F, Sharif S, Saeed R, Durrani N, Jilani D. COVID-19 pandemic- knowledge, perception, anxiety and depression among frontline doctors of Pakistan. BMC Psychiatry. 2020;20(1):459.

[38] Liu CY, Yang YZ, Zhang XM, Xu X, Dou QL, Zhang WW, et al. The prevalence and influencing factors in anxiety in medical workers fighting COVID-19 in China: a crosssectional survey. Epidemiol Infect. 2020;148:e98.

[39] Mattila E, Peltokoski J, Neva MH, Kaunonen M, Helminen M, Parkkila AK. COVID-19: anxiety among hospital staff and associated factors. Ann Med. 2021;53(1):237-46.

[40] Danet Danet A. Psychological impact of COVID-19 pandemic in Western frontline healthcare professionals. A systematic review. Med Clin (Barc). 2021.

[41] Mrklas K, Shalaby R, Hrabok M, Gusnowski A, Vuong W, Surood S, et al. Prevalence of Perceived Stress, Anxiety, Depression, and Obsessive-Compulsive Symptoms in Health Care Workers and Other Workers in Alberta During 
the COVID-19 Pandemic: Cross-Sectional Survey. JMIR Ment Health. 2020;7(9):e22408.

[42] Crowe S, Howard AF, Vanderspank-Wright B, Gillis P, McLeod F, Penner C, et al. The effect of COVID-19 pandemic on the mental health of Canadian critical care nurses providing patient care during the early phase pandemic: A mixed method study. Intensive Crit Care Nurs. 2020: 102999.

[43] Gill S, Hao D, Hirte H, Campbell A, Colwell B. Impact of COVID-19 on Canadian medical oncologists and cancer care: Canadian Association of Medical Oncologists survey report. Curr Oncol. 2020;27(2):71-4.

[44] Smith PM, Oudyk J, Potter G, Mustard C. The Association between the Perceived Adequacy of Workplace Infection Control Procedures and Personal Protective Equipment with Mental Health Symptoms: A Crosssectional Survey of Canadian Health-care Workers during the COVID-19 Pandemic: L'association entre le caractère adéquat perçu des procédures de contrôle des infections au travail et de l'équipement de protection personnel pour les symptômes de santé mentale. Un sondage transversal des travailleurs de la santé canadiens durant la pandémie COVID-19. Can J Psychiatry. 2020:7067437 20961729.

[45] Brophy JT, Keith MM, Hurley M, McArthur JE. Sacrificed: Ontario Healthcare Workers in the Time of COVID-19. New Solut. 2021;30(4):267-81.

[46] Spielberger CD, Gorsuch RL, Lushene RE, Vagg PR, Jacobs GA. STAI: Manual for the State-Trait Anxiety Inventory. Palo Alto, CA: Consulting Psychologists Press.; 1983.

[47] Santangelo G, Sacco R, Siciliano M, Bisecco A, Muzzo G, Docimo R, et al. Anxiety in Multiple Sclerosis: psychometric properties of the State-Trait Anxiety Inventory. Acta Neurol Scand. 2016;134(6):458-66.

[48] Bergua V, Meillon C, Potvin O, Bouisson J, Le Goff M, Rouaud O, et al. The STAI-Y trait scale: psychometric properties and normative data from a large populationbased study of elderly people. Int Psychogeriatr. 2012; 24(7):1163-71.

[49] Potvin O, Bergua V, Meillon C, Le Goff M, Bouisson J, Dartigues JF, et al. Norms and associated factors of the STAI-Y State anxiety inventory in older adults: results from the PAQUID study. Int Psychogeriatr. 2011;23(6): 869-79.

[50] Creighton AS, Davison TE, Kissane DW. The assessment of anxiety in aged care residents: a systematic review of the psychometric properties of commonly used measures. Int Psychogeriatr. 2018;30(7):967-79.

[51] Spielberger CD. State-Trait anxiety Inventory. In: Weiner IB, Craighead WE, editors. The corsini encyclopedia of psychology. Vol 4. hoboken, NJ: John Wiley \& Sons; 2010. p. 1698-9.

[52] Gauthier J, Bouchard S. Adaptation canadienne-française de la forme révisée du State-Trait Anxiety Inventory de Spielberger [A French-Canadian adaptation of the revised version of Spielberger's State-Trait Anxiety Inventory]. Can J Behav Sci. 1993;25(4):559-78.

[53] Karabulut N, Gürçayır D, Yaman Aktaş Y, Kara A, Kızıloğlu B, Arslan B, et al. The effect of perceived stress on anxiety and sleep quality among healthcare professionals in intensive care units during the coronavirus pandemic. Psychol Health Med. 2021;26(1):119-30.

[54] Milgrom Y, Tal Y, Finestone AS. Comparison of hospital worker anxiety in COVID-19 treating and non-treating hospitals in the same city during the COVID-19 pandemic. Isr J Health Policy Res. 2020;9(1):55.

[55] Giusti EM, Pedroli E, D'Aniello GE, Stramba Badiale C, Pietrabissa G, Manna C, et al. The Psychological Impact of the COVID-19 Outbreak on Health Professionals: A Cross-Sectional Study. Front Psychol. 2020;11:1684.

[56] Hacimusalar Y, Kahve AC, Yasar AB, Aydin MS. Anxiety and hopelessness levels in COVID-19 pandemic: A comparative study of healthcare professionals and other community sample in Turkey. J Psychiatr Res. 2020; 129:181-8.

[57] Di Tella M, Romeo A, Benfante A, Castelli L. Mental health of healthcare workers during the COVID-19 pandemic in Italy. J Eval Clin Pract. 2020;26(6):1583-7.

[58] Bahadir-Yilmaz E, Yuksel A. State anxiety levels of nurses providing care to patients with COVID-19 in Turkey. Perspect Psychiatr Care. 2020.

[59] Zhang WR, Wang K, Yin L, Zhao WF, Xue Q, Peng M, et al. Mental Health and Psychosocial Problems of Medical Health Workers during the COVID-19 Epidemic in China. Psychother Psychosom. 2020;89(4):242-50.

[60] Lai J, Ma S, Wang Y, Cai Z, Hu J, Wei N, et al. Factors Associated With Mental Health Outcomes Among Health Care Workers Exposed to Coronavirus Disease 2019. JAMA Netw Open. 2020;3(3):e203976.

[61] Arafa A, Mohammed Z, Mahmoud O, Elshazley M, Ewis A. Depressed, anxious, and stressed: What have healthcare workers on the frontlines in Egypt and Saudi Arabia experienced during the COVID-19 pandemic? J Affect Disord. 2021;278:365-71.

[62] Cai W, Lian B, Song X, Hou T, Deng G, Li H. A cross-sectional study on mental health among health care workers during the outbreak of Corona Virus Disease 2019. Asian J Psychiatr. 2020;51:102111.

[63] Guo J, Liaol L, Wang B, Li X, Guo L, Tong Z, et al. Psychological effects of COVID-19 on hospital staff: a national cross-sectional survey of China mainland. Lancet Psychiatry. 2020.

[64] Liang Y, Wu K, Zhou Y, Huang X, Zhou Y, Liu Z. Mental Health in Frontline Medical Workers during the 2019 Novel Coronavirus Disease Epidemic in China: A Comparison with the General Population. Int J Environ Res Public Health. 2020;17(18).

[65] Alshekaili M, Hassan W, Al Said N, Al Sulaimani F, Jayapal SK, Al-Mawali A, et al. Factors associated with mental health outcomes across healthcare settings in Oman during COVID-19: frontline versus non-frontline healthcare workers. BMJ Open. 2020;10(10):e042030.

[66] Trumello C, Bramanti SM, Ballarotto G, Candelori C, Cerniglia L, Cimino S, et al. Psychological Adjustment of Healthcare Workers in Italy during the COVID-19 Pandemic: Differences in Stress, Anxiety, Depression, Burnout, Secondary Trauma, and Compassion Satisfaction between Frontline and Non-Frontline Professionals. Int J Environ Res Public Health. 2020;17(22).

[67] Cai Q, Feng H, Huang J, Wang M, Wang Q, Lu X, et al. The mental health of frontline and non-frontline medical workers during the coronavirus disease 2019 (COVID-19) outbreak in China: A case-control study. J Affect Disord. 2020;275:210-5.

[68] Rossi R, Socci V, Pacitti F, Di Lorenzo G, Di Marco A, Siracusano A, et al. Mental Health Outcomes Among Frontline and Second-Line Health Care Workers During the Coronavirus Disease 2019 (COVID-19) Pandemic in Italy. JAMA Netw Open. 2020;3(5):e2010185. 
[69] Stojanov J, Malobabic M, Stanojevic G, Stevic M, Milosevic V, Stojanov A. Quality of sleep and health-related quality of life among health care professionals treating patients with coronavirus disease-19. Int J Soc Psychiatry. 2020:20764020942800.

[70] Mohd Noor N, Che Yusof R, Yacob MA. Anxiety in Frontline and Non-Frontline Healthcare Providers in Kelantan, Malaysia. Int J Environ Res Public Health. 2021;18(3).

[71] Ayub M, Arshad D, Maqbool N, Zahid M, Malik RS, Rizvi ZA, et al. Physicians' Attitudes Towards Treating Patients in the Context of COVID-19 Pandemic in Pakistan. Cureus. 2020;12(9):e10331.

[72] Wu B, Zhao Y, Xu D, Wang Y, Niu N, Zhang M, et al. Factors associated with nurses' willingness to participate in care of patients with COVID-19: A survey in China. $\mathrm{J}$ Nurs Manag. 2020;28(7):1704-12.

[73] Rafi MA, Hasan MT, Azad DT, Alam SF, Podder V, Hossain S, et al. Willingness to work during initial lockdown due to COVID-19 pandemic: Study based on an online survey among physicians of Bangladesh. PLoS One. 2021;16(2):e0245885.

[74] Zewudie A, Regasa T, Kebede O, Abebe L, Feyissa D, Ejata F, et al. Healthcare Professionals' Willingness and Preparedness to Work During COVID-19 in Selected Hospitals of Southwest Ethiopia. Risk Manag Healthc Policy. 2021;14:391-404.

[75] Banerjee S, Sarkar S, Bandyopadhyay SN. Survey and analysis of knowledge, attitude and practice among otolaryngologists in a state in eastern India in relation to the coronavirus disease 2019 pandemic. J Laryngol Otol. 2020;134(8):696-702.

[76] Vindegaard N, Benros ME. COVID-19 pandemic and mental health consequences: Systematic review of the current evidence. Brain Behav Immun. 2020;89:531-42.

[77] Seo D, Ahluwalia A, Potenza MN, Sinha R. Gender differences in neural correlates of stress-induced anxiety. $\mathrm{J}$ Neurosci Res. 2017;95(1-2):115-25.

[78] Grahn JA, Parkinson JA, Owen AM. The cognitive functions of the caudate nucleus. Prog Neurobiol. 2008; 86(3):141-55.

[79] Boecker H, Jankowski J, Ditter P, Scheef L. A role of the basal ganglia and midbrain nuclei for initiation of motor sequences. Neuroimage. 2008;39(3):1356-69.

[80] Shenhav A, Botvinick MM, Cohen JD. The expected value of control: an integrative theory of anterior cingulate cortex function. Neuron. 2013;79(2):217-40.

[81] Sommer MA. The role of the thalamus in motor control. Curr Opin Neurobiol. 2003;13(6):663-70.

[82] Singer T, Critchley HD, Preuschoff K. A common role of insula in feelings, empathy and uncertainty. Trends Cogn Sci. 2009;13(8):334-40.

[83] Grill-Spector K, Kushnir T, Hendler T, Edelman S, Itzchak Y, Malach R. A sequence of object-processing stages revealed by fMRI in the human occipital lobe. Hum Brain Mapp. 1998;6(4):316-28.

[84] Shan Y, Shang J, Yan Y, Lu G, Hu D, Ye X. Mental workload of frontline nurses aiding in the COVID-19 pandemic: A latent profile analysis. J Adv Nurs. 2021.

[85] Xiao X, Zhu X, Fu S, Hu Y, Li X, Xiao J. Psychological impact of healthcare workers in China during COVID19 pneumonia epidemic: A multi-center cross-sectional survey investigation. J Affect Disord. 2020;274:405-10.

[86] Wang Y, Wang P. Perceived stress and psychological distress among chinese physicians: The mediating role of coping style. Medicine (Baltimore). 2019;98(23):e15950.
[87] Irshad M, Khattak SA, Hassan MM, Majeed M, Bashir S. Withdrawn: How perceived threat of Covid-19 causes turnover intention among Pakistani nurses: A moderation and mediation analysis. Int $\mathbf{J}$ Ment Health Nurs. 2021;30(1):350.

[88] Groenewold MR, Burrer SL, Ahmed F, Uzicanin A, Free $\mathrm{H}$, Luckhaupt SE. Increases in Health-Related Workplace Absenteeism Among Workers in Essential Critical Infrastructure Occupations During the COVID-19 Pandemic United States, March-April 2020. MMWR Morb Mortal Wkly Rep. 2020;69(27):853-8.

[89] Mas Romero M, Avendano Cespedes A, Tabernero Sahuquillo MT, Cortes Zamora EB, Gomez Ballesteros C, Sanchez-Flor Alfaro V, et al. COVID-19 outbreak in longterm care facilities from Spain. Many lessons to learn. PLoS One. 2020;15(10):e0241030.

[90] Riguzzi M, Gashi S. Lessons From the First Wave of COVID-19: Work-Related Consequences, Clinical Knowledge, Emotional Distress, and Safety-Conscious Behavior in Healthcare Workers in Switzerland. Front Psychol. 2021;12:628033.

[91] Krasavtseva YV, Kiseleva MG, Kasyan GR, Pushkar DY. [Assessment of the psychological status of urologists during the COVID-19 pandemic]. Urologiia. 2020(3):5-9.

[92] Arnetz JE, Goetz CM, Sudan S, Arble E, Janisse J, Arnetz BB. Personal Protective Equipment and Mental Health Symptoms Among Nurses During the COVID-19 Pandemic. J Occup Environ Med. 2020;62(11):892-7.

[93] Elbay RY, Kurtulmus A, Arpacioglu S, Karadere E. Depression, anxiety, stress levels of physicians and associated factors in Covid-19 pandemics. Psychiatry Res. 2020;290:113130.

[94] Shanafelt T, Ripp J, Trockel M. Understanding and Addressing Sources of Anxiety Among Health Care Professionals During the COVID-19 Pandemic. JAMA. 2020; 323(21):2133-4.

[95] Gainer DM, Nahhas RW, Bhatt NV, Merrill A, McCormack J. Association Between Proportion of Workday Treating COVID-19 and Depression, Anxiety, and PTSD Outcomes in US Physicians. J Occup Environ Med. 2021;63(2):89-97.

[96] Jun J, Tucker S, Melnyk BM. Clinician Mental Health and Well-Being During Global Healthcare Crises: Evidence Learned From Prior Epidemics for COVID-19 Pandemic. Worldviews Evid Based Nurs. 2020;17(3):182-4.

[97] Pollock A, Campbell P, Cheyne J, Cowie J, Davis B, McCallum J, et al. Interventions to support the resilience and mental health of frontline health and social care professionals during and after a disease outbreak, epidemic or pandemic: a mixed methods systematic review. Cochrane Database Syst Rev. 2020;11:Cd013779.

[98] Chen Q, Liang M, Li Y, Guo J, Fei D, Wang L, et al. Mental health care for medical staff in China during the COVID19 outbreak. Lancet Psychiatry. 2020;7(4):e15-e6.

[99] Que J, Shi L, Deng J, Liu J, Zhang L, Wu S, et al. Psychological impact of the COVID-19 pandemic on healthcare workers: a cross-sectional study in China. Gen Psychiatr. 2020;33(3):e100259.

[100] Shechter A, Diaz F, Moise N, Anstey DE, Ye S, Agarwal S, et al. Psychological distress, coping behaviors, and preferences for support among New York healthcare workers during the COVID-19 pandemic. Gen Hosp Psychiatry. 2020;66:1-8. 